\title{
1. Screen Narrative in the Digital Era
}

\author{
Ian Christie and Annie van den Oever
}

Wordless storytelling is natural. The imagetic representation of sequences of brain events, which occurs in brains simpler than ours, is the stuff of which stories are made.

- Antonio Damasio, The Feeling of What Happens $(2000,188)$

"Stories" are inescapably central to modern media discourse, not only in traditionally narrative entertainment media, such as television, cinema, and theater, but also in social media (Twitter, Instagram, Facebook, blogging), and "new media" (online gaming, VR). Furthermore, telling or having "a story" is widely deemed essential in advertising, commerce, and social life. Not surprisingly, teaching and coaching in storytelling has become a major industry. "Creative writing" courses are heavily subscribed and advice is ubiquitous.

Storytelling was clearly of major importance in the development of cinema and television, as well as new forms of printed and graphic media, during the early twentieth century. But even if these media were new (or, more accurately, new inflections of existing screen and print forms), storytelling is as old and universal as any sense of consciousness, according to the neuroscientist, Antonio Damasio. He further suggests that the "natural pre-verbal occurrence of storytelling" may be why drama and later written narratives emerged, "and why a good part of humanity is currently hooked on movie theatres and television screens" (Damasio 2000, 188). For Damasio, echoing what Hugo Münsterberg (1916) claimed just over a century ago, "movies are the closest external representation of the prevailing storytelling that goes on in our minds" (188). ${ }^{1}$ However, in trying to account for "the making of core consciousness," his concern is less with the mind/cinema analogy than locating storytelling in an evolutionary sequence that starts with "mapping," which "probably begins relatively early both in terms of evolution and in terms of the complexity of the neural structures required to create narratives" (189). He therefore concludes that "telling stories precedes language, since it is in fact a condition for language, and it is based not just in the cerebral cortex but elsewhere in the brain" (189).

But if it is a precondition for language itself, then a more developed storytelling ability is also a defining feature of what we call "culture." In his 
landmark book, The Interpretation of Cultures, anthropologist Clifford Geertz $(1973,89)$ formally defined culture as "a system of inherited conceptions expressed in symbolic forms by means of which [wo]men communicate, perpetuate, and develop their knowledge about and attitudes toward life." However, he also defined it more succinctly as "stories we tell ourselves about ourselves." Gaining a perspective on the present or the immediate is always difficult. Therefore, we might wonder whether the contemporary preoccupation with "stories" marks an intensification of what has long been latent in our culture, or whether it signals a new direction, perhaps comparable to the surge of concern with "media" in the 196os. At any rate, it is an obvious priority for the Key Debates series. In this volume, we prioritize new phenomena in the field (complex narration, puzzle films, transmedia storytelling), trying to identify the "key issues" amid the vast amount of discussion and analysis on the topic, while also indicating what seem to be the most promising paths in research.

\section{From the Archive}

The major motivating question behind this latest book in our series is: Has storytelling - or story-following - changed decisively, either during the era of "cinema" or, perhaps more pertinently, in the postcinema era of digital and interactive media? We find ourselves wondering about the relationship between "story" as a term used in everyday as well as academic discourse. Does all narrative form deal with what we would call "stories?" And, indeed, does overuse of the term "story" devalue or detract meaning from what we would formerly have called a story? While creating the book (as we would say in storytelling mode), we had in mind two key moments in conceptualizing the nature of "story": one a "delayed" essay by Walter Benjamin, and the other a somewhat neglected essay by Christian Metz.

Like much of Benjamin's work, "The Storyteller" was written in the 193os, but only reached its wider audience in an English translation presented by Hannah Arendt in $1969 .{ }^{3}$ In it, Benjamin lamented the end of the oral era and the loss of storytelling as a social and fundamentally communal practice within the oral tradition. ${ }^{4} \mathrm{He}$ defined storytelling as a participatory art, led by a skilled storyteller whose social function was defined by his or her community. Listening to a story in such a context meant taking part by actively responding to the questions and gestures of the storyteller, in what Benjamin considered a two-way communication rather than a monologue. This "culture of participation" - as it would be called today if we take the 
discussions of current transmedia-storytelling practices as a model - was central to Benjamin's text.

What gave this practice of storytelling its most basic authority? For Benjamin, stories were cultural phenomena with a specifically social function. They did not simply derive from the need to share interesting experiences with a community, but a more deeply felt human need: to provide real-life examples of coping with the mystery of human reality. Hence, one did not just listen to a storyteller: one received advice. This is one of the crucial statements in "The Storyteller." If storytellers always offered advice, the question must be: Is there still room for this social practice in the modern world (of the 1930s)?

Benjamin's answer was negative. With some nostalgia, he observed that socially driven storytelling practices rooted in the oral tradition were coming to an end for various reasons. ${ }^{5}$ He identified the most basic as a change in the communicability of experience itself and, most importantly, of the experience of death. What used to be an experience of the community had disappeared from public life: the waiting, the soft talking, the walking in and out of the house for the days it took to die, people suddenly coming together to say farewell to the dying person. This social practice was described in the famous 1886 novella The Death of Ivan Ilyich by Leo Tolstoy, when it was already slowly disappearing, together with storytelling as a social practice. If we wonder why there is such a keen interest in Benjamin's text among scholars today, ${ }^{6}$ we must acknowledge not only its nostalgia but also its evocation of communities "telling stories to each other."

The trend that has provoked renewed interest in Benjamin's essay could be described as pointing away from criticism and interpretation, hermeneutics, the medium-specificity of narratives and formal narrative structure, toward stories as reflections of experience, as affecting experience, creating absorption in the storyworld. These shifts also seem to be reflected in renewed attention to the work of Christian Metz, one of the founding figures of modern film theory. Metz has been represented in various ways, but only recently as a phenomenologist. He wrote about Narratif (with a capital N) in a 1966 essay which addressed stories and storytelling as general phenomena, writing of the fundamental anthropological gesture of storytelling from an explicitly phenomenological perspective (Chateau and Lefebvre 2014, 23-28). ${ }^{7}$ His primary question was: Which qualities do all narratives likely possess in order to be recognized as such?

His answer did not attract much attention, probably because the emergent study of narratology did not need the input of this sort of phenomenology 
- especially since, in this text, Metz was not seeking the specific sense or phenomenological qualities of cinematic or literary narratives. His aim was to explore and clarify the preconditions that make the project of a Semiology of Narrative possible. As narratology was embarking on an analysis of signification at the time, this would first require a parsing of the world in terms of sense: the "naive," presemiological, "lived" sense of what a narrative is. In line with Metz's famous "impression of reality," Narrative was termed the "impression of narrative." With these reflections, Metz pointed to what precedes and makes possible narratology as the study of narrative in cinema - its phenomenological condition of possibility. We can "scientifically" study narrative because we already have a nonscientific sense of what narrative "is," of its qualities.

There have been other significant story-related transitions taking shape in the digital era, which digital technologies have helped to create. In particular, the twenty-first-century display devices and new screen technologies tablets, watches, glasses, wearables - all typically used by individuals, intimately and repetitively, creating large cohorts of well-trained users in the process. Several new practices of use have sprung from these. Above all, there is the film viewer shifting between devices to watch multiple images; and all these devices invite viewers to become possessive of the film image, to become possessive viewers, a term coined by Laura Mulvey in 2006. ${ }^{8}$ By manipulating their smart devices, they take control over the image, manipulate the story flow, return to moments of special interest, touch the image, enlarge it, and so on. What does this do to their role as viewers, to their knowledge of film, or stories told on film?

\section{Storytelling on Demand}

Jason Mittell (2006) famously stated that narrative complexity became the norm on American multichannel television from the 1990s onward. "Quality television" became an option for networks such as HBO, aiming at a section of the audience solely invested in high-quality entertainment. Mittell argues that the popularity of such television series has helped create a new mode of active and reflexive viewer engagement. Ultimately, the film industry was also to profit from the new narrative skills viewers acquired over the years, mainly by binge-watching "on demand" and narratively complex television series, often for many hours each week, if not daily. Most viewers will have spent more time watching complex television than complex films. Thus, the "training" effects of television have tended to be evident. Not surprisingly, 
cinema has been affected by the long-term impact of television series on viewers, as it has been by the effects of video and computer gaming.

Many films made for the cinema from the 19gos onward tell stories which are "complex." Examples include Wild at Heart (1990), Pulp Fiction (1994), The Usual Suspects (1995), The Matrix (1999), The Sixth Sense (1999), Memento (2000), Mulholland Drive (2001), Adaptation (2002), Eternal Sunshine OF THe SPOTless Mind (2004), and InCEPTion (2010). These films have "embraced a game aesthetic, inviting audiences to play along with the creators to crack the interpretive codes to make sense of their complex narrative strategies," as Mittell wrote in his seminal article "Narrative Complexity in Contemporary American Television" (2006, 36). His explanation was that "narratively complex programs" which were "constructed without fear for temporary confusion for viewers,"9 may have triggered a sense of "temporary disorientation and confusion" in viewers, but they also provoked, and allowed "viewers to build up their comprehension skills through long-term viewing and active engagement" (38). In the end, these complex programs turned viewers into what Mittell described as "amateur narratologists" (38).

This process was supported by fan cultures which would have been impossible in terms of scale, speed, and intensity without social media. Fans found ways of reaching out to one another on global fan blogs; and having sophisticated discussions regarding the tricks and twists used in their favorite series. Other phenomena that have affected storytelling practices today include: fan cultures nourishing the narratologist in viewers who end up knowing as much about story structures and techniques as scholars, if not more; fan cultures being nurtured by television's writing teams or more often by its producers; fans shifting from being solely consumers to becoming occasional producers, as "prosumers"; and some fans going from creating forms of cross-media communication about their favorite storyworlds to using sophisticated storytelling methods themselves, diverting from and adding to popular stories online in what has been referred to, since 2003, as transmedia storytelling (see Chapter 6).

Amateur narratologists are fans who like to be challenged and tested - by the complex narrative forms that can be explained by professional narratologists, such as the notoriously confusing form of metalepsis, discussed by John Pier in the Living Handbook of Narratology (2013), and now regularly found in mainstream, industry-produced films such as THE MATRIX and INCEPTION. This phenomenon implies that not only do audiences understand such puzzling complexities, they obviously appreciate them, as fan sites testify (and as Kiss and Willemsen explore in Chapter 4). 


\section{About the Book}

In the first part of the book, Theory in Contemporary Contexts: Reassessing Key Questions, Jan Baetens poses key questions regarding visual and literary forms of storytelling. His investigation of "Stories and Storytelling in the Era of Graphic Narrative" leads him to conclude that given the diversity and inequality of stories, a "global," cross-medial approach to stories and storytelling is problematic. He also argues that, although graphic narrative (as in graphic novels) is not a field that has the same cultural and economic importance as cinema, it offers a significant opportunity. Given the diversity of the field and the quick changes that characterize it, it can serve as a useful echo chamber for ideas and hypotheses to test in the broader fields of film studies and storytelling in general. Against this background, Baetens proposes the study of graphic storytelling as a key domain in the larger field of cultural narratology, of which film studies is a subfield.

In the third chapter, on iconographic storytelling, Vincent Amiel deals with visual figurative thought: a system of meaning specific to images, which owes nothing to the logic of writing. He starts by acknowledging that normally iconographic and narrative systems are placed in opposition to one another, as if specific qualities inherent to the very principle of the image would be unable to enter the storytelling process. The heart of the chapter consists of an in-depth discussion of combinations of images which, though inscribed in the unfolding process of a film, nevertheless suggest discontinuity and a different logic of articulation. In his discussion of this logic, which is very different from classical narrative, Amiel shows how, by way of collage, overlay, inlay, or objectification, such offset images complicate the flow of films, and generate networks, ridges, or narrative systems that deliberately confuse the course of the film. In what is a plea for the study of the relations between images which are part of a nonlinear, iconographic logic, Amiel analyzes such combinations of images which establish a dialogue on the screen, outside of the conventional rules of successive presentation.

The fourth chapter examines a set of phenomena grouped together under the label of "complex narratives." These emerged from the mid-199os onward in popular cinema and in serial television, and have continued to increase in prominence and popularity ever since. Miklós Kiss and Steven Willemsen present a valuable overview of the field, before offering an alternative analysis of the various experiences of narrative complexity in contemporary cinema, asking the question: Why would an experience of confusion triggered by puzzle films be gratifying? This involves a reconceptualization of story and storytelling complexity in film from a 
cognitive perspective. Next, they analyze how different types of complex movies evoke different kinds of cognitive puzzlement in their viewers. Interestingly, they maintain that feeling "challenged" by complex movies is more important to fans than solving the puzzles presented in films which dare to confuse viewers, boldly leaving much interpretive and analytical work to their cognitive and interpretive competences. The challenge appears to be gratifying, and leaves room for many kinds of creative, intellectual, analytical, and interpretive skills and processes. This, in a mainstream context, is novel. Kiss and Willemsen argue that impossible puzzle films can best be seen as the product of an era that is saturated with both media and narratives. In such a context, films that are cognitively challenging and intellectually intriguing are considered attractive by viewers accustomed to the increasing amounts of mediation, narrativity, and complication in popular fiction.

"Storification"; Or, What Do We Want Psychology and Physiology to Tell Us about Screen Stories?" offers a reflection on the two immediate contexts from which this volume springs. One, as noted above, is the omnipresence of "story" as a vade mecum in contemporary culture and society. The other is the promise held out by two new sciences, evolutionary biology and neurobiology (cognitive psychology or physiology), to address the most fundamental mainsprings of our relationship to stories. How is it that, as a species, we alone are innately attuned to storytelling? - a question that Brian Boyd set out to explore in his On the Origin of Stories (2009). And what is the cognitive apparatus that enables us to make and attend to stories in many media? The work of Torben Grodal has sought to bring film within the orbit of evolutionary biology; while David Bordwell has pursued issues of how we interpret filmic narrative across a rich series of books, articles, and blogs, with exemplary attention to researchable case studies. While both of these remain contentious to some degree, and have indeed deliberately courted controversy on occasions, they remain essential reference points as we contemplate the future of scholarship on screen stories.

In her chapter on "Transmedia Storytelling: New Practices and Audiences," Melanie Schiller argues that transmedia storytelling is driven by media users and fans with an increasing desire for transmedia experiences. The phenomenon fits into the broader context of a growing popularity of usergenerated content and fan productions. Although fostered by the industries, it is actively contributed to by media-savvy fans creating extensions to popular stories such as HARry PotTer (2001-2011) or The MAtrix (19992003). Schiller notes that all this is typically marked by a flow of content across multiple media platforms, and that for a proper understanding of these 
new practices of storytelling, it is important to distinguish them from media adaptations or remediations which are unidirectional movements from one medium (book) to another (theater). She shows that transmedia storytelling is much broader: it involves the expansion of a story through storytelling activities of participating fans contributing to the story's universe in a range of different semiotic systems and historical media practices, all of which enhance the construction of the overall transmedia storyworld.

In PART II, History and Analyses, José Moure reflects on the type of story told in a range of films from Michelangelo Antonioni. More particularly, he shows in an in-depth analysis of a series of his films - from CRONACA DI UN AMORE (1950) to IDENTIFICAZIONE DI UNA DONNA (1982) - that Antonioni was drawn to telling stories without an end or, perhaps, it would be more accurate to speak of them as stories with endless endings which spiral down like a staircase in a dream, without ever allowing audiences to reach the end. These stories resolve in indecisiveness, as Moure argues. In as far as Antonioni's films are constructed, characteristically, around a feeling of loss, and plotted along erratic, dissolving trajectories which efface or displace the initial emptiness without filling it, their stories are emblematic of a certain kind of European art cinema in a specific era.

Dominique Chateau devotes a chapter to the analysis of David Lynch's much-admired 2017 television series TwIN PEAKs 3, what might have been considered the apotheosis of complex narrativity on American television, for all its virtuosity and challenges to viewers. Chateau opens his chapter with praise by Matt Fowler deeming Twin PEAKs 3, much like Chateau, "the most perfect and uncanny audiovisual product" ever made: "a true artistic force that challenged just about every storytelling convention we know." Chateau argues that TwIN PEAKs 3 is unapologetically and objectively "strange" given its double use of doppelgänger figures, its genre hybridity, its endless list of dream cues, the hypnotic use of slowness, and dream thoughts shifting between significant and insignificant details (if ever there was such a thing in the Freudian "dreamwork"). Chateau analyzes Twin Peaks 3 not as a film about dreams but as a "film that dreams," as he puts it. By way of a conclusion, he proposes to look at David Lynch's "18-hour movie" - not a series, according to Lynch - as strange in a certain way: everyday, yet grotesquely distorted, thus emphasizing the ambiguous relationship between strangeness and the familiar.

Finally, in this section, the philosopher, Sandra Laugier, considers the "moral relevance" of such popular series as GAME of Thrones (2011- ). Based on her regular columns in the French newspaper Libération, this chapter draws a parallel between the position of the American philosopher, 
Stanley Cavell, who has written extensively about classic Hollywood cinema as "moral education," and Laugier's own view on the moral relevance of contemporary TV. For Cavell, the educational value of popular culture is not anecdotal, but defines what we understand by "popular" and "culture." Laugier finds the same significance in the popular series of today, such as The Walking DeAd (2010- ) and above all Game of Thrones, which she defines as "polyphonic," containing as they do many singular expressions, arguments, and debates, and creating for their loyal viewers "a moral atmosphere." Against those who would see such series as merely escapist, Laugier argues that they represent "an empowerment of the audience, who are able by virtue of their experience and preferences to reach their own judgment." Since the radical turn that US series took in the 1990s with ER (1994-2009) and THE WEST WING (1999-2006), she argues that viewers have been initiated into "new forms of life and new, initially opaque vocabularies that are not made explicit, without any heavy-handed guidance or explanation, as there was in earlier productions." As a public philosopher, concerned with ethics in the modern world, Laugier believes that it is the "new narrativity" of such series that makes for their moral relevance. And against those who would decry the alleged sexism of GAME OF THRONES, she insists that it "releases or reveals women's capacity for action, for the populations of the South and slaves, as liberated by the Khaleesi ... democracy is coming." Indeed, she claims, "it is women, at least as much as men, who represent [a new] form of perfectionist aristocracy: Catelyn, Brienne, Arya, Yara, and of course the Khaleesi." Laugier writes as a series enthusiast, as a fan, claiming that GAME of THRONEs is, in fact, more realistic than historical fiction, finding "its realism in proximity to the human, and its emotional strength in humanity and the modest heroism of characters doomed to death."

PART III, Discussions, is devoted to questions about new forms of storytelling prompted by developments in mainstream television and the everyday ubiquity of smartphone use respectively. In the first discussion, television producer and television scholar John Ellis reflects on new phenomena in storytelling practices in television today. As the author of Visible Fictions (1982) and other books on mainstream television between the 1960 and 1980 s, he famously described watching TV as a very specific activity for viewers, comparable to "working through," as in psychoanalysis. However, we ask whether this is still true of watching television today. Do networks still allow their viewers to "work through" the themes which trouble and concern them today and, if so, what types of stories are needed to facilitate such a process? As a former television producer, now actively involved in researching past practices of television technique, John Ellis is ideally 
positioned to discuss the levels of investment in production values demanded by Quality TV, and the narrative complexity and character development (particularly of secondary characters) that serial space allows.

Roger Odin's chapter, "The Single Shot, Narrativity, and Creativity in the Space of Everyday Communication" continues the exploration begun in his contribution to an earlier volume, Audiences, in which he outlined a theory of the significance of mobile cameraphones marking a new stage in the status of "film language," whereby it has become independent of cinema and of films per se, as simply a means of communication (Odin 2012, 169). Here, Odin takes the common figure of a continuous mobile image, or "tracking shot," to explore "what happens when nothing is happening" in live communication via cameraphones. In such a continuous image, he notes, "a process of narrativization is often introduced," and it is this that makes his chapter a valuable addition to the phenomenology of mobile communications. His detailed account of a Skype call between a young couple and grandparents who are abroad irresistibly recalls an illustration that appeared in Punch in 1878 , in which a Victorian couple was shown communicating from London with their children in Ceylon by means of "telephonoscope."”o This anticipation of what we know as Skype was prompted by the launch of Edison's Phonograph, an early landmark in the nineteenth-century communications revolution. Odin's account of this aspect of our everyday reality demonstrates how "narration passes through a combination of different devices; and it really seems to be a new way of telling or showing." It is, he suggests, yet another example of our ability to "live creatively," in the phrase used by the influential psychoanalyst, D.W. Winnicott.

PART IV of the book is devoted to a group of reflections on practicalities, each of which also has a personal dimension. Stories are created, adapted, and reworked by professionals within the film and television industries, and two of these chapters take the form of dialogues between the editors and practitioners, aiming to tap into their practical experience of shaping stories in the contemporary media world, while the other represents a blogger's perspective on a unique recent experiment in British television.

This section opens with the Dutch writer and filmmaker, Eric de Kuyper, recalling his experiences of collaborating with the well-known Belgian filmmaker and his longstanding friend, Chantal Akerman, who took her own life in October 2015. De Kuyper describes their approach to Proust's celebrated novel-sequence $A$ la recherche du temps perdu, widely regarded as essentially "unadaptable," which resulted in Akerman's film LA CAPTIVE (2000). He describes his friend, already famous at the age of 25 for the uncompromising JEANNE DiELMAN, 23 QUAI DU COMMERCE, 1080 
BRUXelles (1975), as an obsessive reader, who drew him to reading Proust. When they embarked on the adaptation, he was curious to discover how she would approach Proust's complex and labyrinthine novel, with its large cast of characters, rich evocation of a period and society and, above all, its intricate plot. He was soon to discover that she was neither fascinated by Proust's complexity nor the plot. In general, she thought of the film story as characters in specific situations and characters in different locations, De Kuyper says, and in this case, her focus was fully on the theme of "jealousy in a love affair" and the story of Marcel and Albertine. In retrospect, what they ended up doing was reworking Proust for LA CAPTIVE: to fit her vision of what a film by her should be about.

Ian Christie reflects on the history of "extending" and adapting literary texts by way of introduction to Luke McKernan's study of the BBC series Dickensian. A prolific blogger specializing in aspects of early cinema (as well as a curator at the British Library), McKernan is the coeditor of a standard reference work on the many screen adaptations of Shakespeare, as well as a guide to "Victorian filmmaking," hence his interest in Tony Jordan's 2015 series is understandable. Jordan has been a pivotal figure in British popular television over three decades, scripting the major BBC soap opera EASTENDERS (1985-) and creating such innovative series as LIFE ON MARS (2007). With DickENSIAN, he created a "fully realized alternative world" composed of characters and partial storylines drawn from the novels of Charles Dickens. Extracting episodes from the novels, which first appeared in serial form, like much nineteenth-century fiction, was already a common practice in Dickens's lifetime - he himself gave dramatized readings on both sides of the Atlantic. And Dickens would become one of the most frequently adapted sources for both early cinema and television. But as McKernan argues, DicKENSIAN attempted something more ambitious: creating a synthesized single narrative composed of identifiable fragments from otherwise separate "storyworlds." Although attracting much attention, and considerable praise, the series fell victim to a common fate in contemporary long-form screen fiction: it was not recommissioned, although, of course, it remains accessible in nonbroadcast formats.

The importance of music in screen storytelling can hardly be underestimated, and was often discussed during the preparation of this volume. Yet, rather than commission a chapter analyzing current trends in film or television composition, we asked the conductor Robert Ziegler, who works with live orchestral concerts as well as soundtrack recording, for his thoughts about the practice of musical accompaniment today. The dialogue with Ziegler led to a brief discussion of the work of Carter Burwell who, as Ziegler 
notes, is very good at explaining what he does as a film composer. On his work for Three Billboards Outside Ebbing, Missouri (2017), Burwell notes that as the story and the relationships develop, "[Mildred's] themes intertwine until, by the last couple of reels, they're barely recognizable." In many ways, this kind of analysis could be applied to film music at almost any moment during the last hundred years. But as a sign of the times, Burwell (et al. 2013) is also actively interested in discovering what neuroscience can reveal about the unconscious part that music plays in our narrative absorption.

The potential of the cognitive sciences to explain much more about what is involved in our familiar practices of story-making, story-following, and story-sharing has been recognized since the beginning of this century. As long ago as 2003, David Herman's collection, Narrative Theory and the Cognitive Sciences, identified "a crossroads where cognitive and social psychology, linguistics, literary theory, and [...] 'cognitive narratology' intersect" (Herman 2003). Whether the fissiparous community of screen scholars is convinced of this direction remains debatable. But we hope that the present volume reflects at least some of the most promising current and future sites of activity.

\section{Notes}

1. In Audiences (Christie 2012), the psychologist, Tim Smith, referred to Münsterberg's belief that films "externalized the audience's inner world" (172).

2. In his essay about Balinese cockfighting, Geertz summarized the significance of a story as "a Balinese reading of Balinese experience, a story they tell themselves about themselves" $(1973,448)$. For a large-scale application of Geertz's idea to the field of film studies, see Stories We Tell Ourselves (2009), online at http://www.bfi.org.uk/sites/bfi.org.uk/files/downloads/bfiopening-our-eyes-stories-we-tell-ourselves-report-2006.pdf.

3. Hannah Arendt selected the essay for Illuminations, a volume of Benjamin's essays, with a now classic essay by Arendt about Benjamin's life in dark times. Typically, his essays expressed a deep affinity with Kafka, Baudelaire, Proust, Leskov (the central figure in "The Storyteller"), and Brecht.

4. In yet another seminal text springing from this dark period in history, these changes were also discussed, although in terms of representation: see Mimesis (Auerbach 2003). Auerbach started working on this book in the mid-1930s, yet Mimesis was only published in 1946, a mere decade after "The Storyteller."

5. However, Benjamin saw relics of the tradition in some storytellers in the modern era, including Leskov. 
6. "The Storyteller" (like "The Work of Art in the Age of Mechanical Reproducibility") has been discussed intensively over the decades in the Germanspeaking countries, yet long receiving considerably less attention in the Anglo-American, even if Arendt's essay did raise attention for Benjamin and this essay in the 1970s. Recently, however, this essay attracted fresh attention in, for instance, an elaborate reflection by Charles May (2014).

7. We are grateful for the input of Dominique Chateau and Martin Lefebvre and in the following paragraph we draw on their reflections and conversation on the topic. See also their reflection on Metz and Phenomenology (Chateau and Lefebvre 2014). They argued that "Remarques" grew out of a moment in Metz's thinking when his phenomenological "considerations for sense" intersected with the "semiological considerations or conditions for signification." The first section of their essay is entitled "Semiology as Phenomenology or Phenomenology as Semiology."

8. Laura Mulvey (2006) devoted a whole chapter to the characteristics of this type of viewer, born in the age of video and developing quite quickly in the age of smart technologies. As she expressed, Mulvey took inspiration from Raymond Bellour's reflections on the changing viewing conditions available to the film viewer.

9. To his many examples also belong: Lost, Alias, Veronica Mars, The X-Files, Desperate Housewives, and Twin Peaks. Mittell argues that viewers watch such programs, "at least in part to try to crack each program's central enigmas - look at any online fan forum to see evidence of such sleuths at work" $(2006,38)$.

10. This cartoon, drawn by Gerald Du Maurier, is reproduced at https:// en.wikipedia.org/wiki/Telephonoscope\#/media/File:Telephonoscope.jpg

\section{References and Further Reading}

Auerbach, Erich. 2003 [1946]. Mimesis: The Representation of Reality in Western Literature. Translated by Willard Trask. Princeton: Princeton University Press.

Benjamin, Walter. 1969. Illuminations: Essays and Reflections. Edited by Hannah Arendt. Translated by Harry Zohn. New York: Harcourt, Brace and World.

Burwell, Carter, Ethan Coen, Joel Coen, Aniruddh Patel, and Alec Baldwin. 2013. "Art of the Score." YouTube video, 1:31:26. From a World Science Festival panel, moderated by Alec Baldwin. November 21, 2013. http://www.carterburwell.com/main/carter_burwell.shtml.

Chateau, Dominique, and Martin Lefebvre. 2014. "Dance and Fetish: Phenomenology and Metz's Epistemological Shift.” October 148 (Spring): 103-132.

Christie, Ian, ed. 2012. Audiences: Defining and Researching Screen Entertainment Reception. Amsterdam: Amsterdam University Press.

Damasio, Antonio. 2000. The Feeling of What Happens. Body, Emotion and the Making of Consciousness. London: Vintage.

Geertz, Clifford. 1973. The Interpretation of Cultures. New York: Basic Books. 
Herman, David, ed. 2003. Narrative Theory and the Cognitive Sciences. Stanford, CA: CSLI.

May, Charles. 2014. "Walter Benjamin: 'The Storyteller: Reflections on the Works of Nikolai Leskov.”' Reading the Short Story (blog), May 1, 2014. http://may-on-the-short-story.blogspot. $\mathrm{nl} / 2014 / 05 /$ walter-benjamin-storyteller-reflections.html.

Metz, Christian. 1966. "Remarques pour une phénoménologie du Narratif." In Essais sur la signification au cinéma, 23-28. Paris: Klincksieck.

Mittell, Jason. 2006. "Narrative Complexity in Contemporary American Television." The Velvet Light Trap, 58 (Fall): 29-40.

Mulvey, Laura. 2006. Death $24 x$ a Second: Stillness and the Moving Image. London: Reaktion Books.

Münsterberg, Hugo. 1916. The Photoplay: A Psychological Study. New York: D. Appleton and Company.

Pier, John. 2013. "Metalepsis." In The Living Handbook of Narratology, edited by Peter Hühn et al. Hamburg: Hamburg University Press. http://wikis.sub.uni-hamburg.de/lhn/index.php/ Metalepsis.

UK Film Council. 2009. Stories We Tell Ourselves: The Cultural Impact of UK Film 1946-2006. Great Britain: Narval Media/Birckbeck College/Media Consulting Group. http://www.bfi.org.uk/ sites/bfi.org.uk/files/downloads/bfi-opening-our-eyes-stories-we-tell-ourselves-report-2oo6. pdf. 